\title{
O COGITO DO ADEUS O SUJEITO EM AUTODESCONSTRUÇÃO
}

\author{
Fernanda Bernardo* \\ "Le sujet est une fable" \\ (DERRIDA, 1992. p. 279)
}

"Je suis endeuillé, donc je suis"

(DERRIDA, 1996)

Enfim, enfim quebrara-se realmente o meu invólucro, e sem limite eu era. Por não ser, eu era. Até o fim daquilo que eu não era, eu era. O que não sou eu, eu sou. Tudo estará em mim, se eu não for; pois "eu" é apenas um dos espasmos instantâneos do mundo. Minha vida não tem sentido apenas humano, é muito maior - é tão maior que, em relação ao humano, não tem sentido. [...]

Mas agora, eu era muito menos que humana - e só realizaria o meu destino especificamente humano se me entregasse, como estava me entregando, ao que já não era eu, ao que já é inumano.

E entregando-me com a confiança de pertencer ao desconhecido. [...] E tal entrega é o único ultrapassamento que não me exclui. Eu estava agora tão maior que já não me via mais. Tão grande como uma paisagem ao longe. Eu era ao longe. ${ }^{1}$

$* * *$

\section{Resumo}

O Cogito do adeus. O sujeito em auto-desconstrução é o texto da comunicação apresentada no Colóquio Internacional de homenagem a Jacques Derrida, aquando do $10^{\circ}$ aniversário da sua morte, que decorreu na Universidade de Uberlândia, de 29 de Setembro a 3 de Outubro de 2014, com o título O sujeito pós-metafísico.

* Doutora em Filosofia. Professora na Faculdade de Letras da Universidade de Coimbra. E-mail: fernandabern@gmail.com

1 LISPECTOR, C, A paixão segundo GH. Rio de Janeiro: Nova Fronteira, 1979. p. 174-175. 
Começando por referir e por sublinhar, quer a ficcionalidade do dito sujeito metafisico (autonómico e egocrático) - «o sujeito é uma fábula» (Derrida dixit) -, quer a pertinência e o desafio de sempre da interpelação da questão do sujeito, uma questão sem idade, enfatizaremos a seguir, nesta data enlutada para os leitores/as leitoras e amigos/amigas de Jacques Derrida, o carácter originário do luto, da experiência do luto, para dar conta da experiência de identificação subjectiva pela via da relação de in-finita ex-apropriação do «eu» ou do dito sujeito com a singular anterioridade da língua (do outro - no sentido de proveniente do outro como a própria vinda do outro) ou da marca, assim dando conta, quer da experiência in-finita de não identidade a si do dito sujeito, quer do facto de ser desta mesma experiência de não-identidade a si ou de ex-apropriação que irrompe quer a pulsão de soberania, inerente ao sujeito soberano, quer a pulsão de incondicionalidade que giza a aporia da força frágil do sujeito em auto-desconstrução.

Palavras-chave: Derrida. Sujeito. Luto Originário. Ex-Apropriação. Força Frágil. Incondicionalidade

\section{Résumé}

Le cogito de l'adieu. Le sujet en auto-déconstruction, c'est le texte de la communication présentée au Colloque International d'hommage à Jacques Derrida qui a eu lieu, lors de la 10ième année de sa mort, à L'Université de Uberlândia, du 29 septembre au 3 octobre 2014, sous le titre Le sujet post-métaphysique.

Tout en commençant par repérer et souligner, soit la fictionalité dudit sujet métaphysique (autonomique et egocratique) - «Le sujet est une fable» (Derrida dixit) -, soit la pertinence et le défi de toujours de l' injonction de la question du sujet, une question sans âge, nous remarquerons par la suite, lors de cette date endeuillée pour les lecteurs/lectrices et ami(e)s de Jacques Derrida, le caractère originaire du deuil, de l'expérience du deuil, afin de discerner l'expérience d'identification subjective par le biais du rapport d'in-finie ex-appropriation avec la singulière antériorité de la langue (de l'autre, au sens de venue de l'autre comme sa venue même) ou de la marque, en dévoilant de la sorte, et «l'expérience in-finie de non-identité à soi» dudit sujet, et que de cette expérience même de non-identité à soi ou d'ex-appropriation jaillit soit la pulsion de pouvoir, propre au sujet souverain, soit la pulsion d'inconditionnalité qui tisse l'aporie de la force faible du sujet en auto-déconstruction.

Mots-clefs : Derrida. Sujet. Deuil Originaire. Ex-Appropriation. Force Faible. Inconditionnalité

$$
* * *
$$


[...] "e sem limite eu era" - eu, "eu era ao longe"[...]. Este incipit fabuloso de Clarice Lispector com mais de uma intenção - com uma tríplice intenção, pelo menos: em primeiríssimo lugar para, do coração, vos saudar com o idioma único e no idioma único desta vossa escritora que tanto honra a língua portuguesa; em segundo lugar, com a intenção de, algures, aqui, neste limiar tão fabulosamente apontado por Lispector para significar o "ultrapassamento" da "lei do gênero", do limite de todos os gêneros (humano-inumano, literatura-filosofia, masculino-feminino etc.), começar justamente por realçar a secreta ressonância deste limite sem limite (limus, limes) que, como sabemos, denominado por khor ${ }^{2}$ e pelo messiânico ${ }^{3}$, apostrofa, apela, desafia, põe à prova e magnetiza a singularidade idiomática, a hiper-radicalidade e a hipereticidade da desconstrução derridiana ${ }^{4}$, não menos que a precipitação da sua ineliminável apor-eticidade ${ }^{5}$, designando a insônia vigilante de uma véspera que nunca se faz dia - ["c'est pas demain la veille"é um sintagma que não saía da boca de Derrida] - de onde se eleva o ímpeto da incondicionalidade e, portanto, do irredentismo do pensamento, da fé, do poema, da literatura e, no fundo, da arte ou das artes em geral na sua transversalidade de princípio.

E este incipit fabuloso de Clarice, em terceiro lugar e finalmente, com a intenção de, ainda neste mesmo limiar, começar também por me pôr à escuta da ressonância do título geral do evento no qual se insere o nosso colóquio de homenagem, a nossa saudação admirativa e saudosa a Jacques Derrida (1930-2004): O Sujeito Pós-Metafisico. Uma escuta da qual brota um enorme feixe de questões, de que passo a enunciar algumas, porque, de certa forma, elas como que abrem o angulo a partir do qual tentarei perspectivar e aproximar aqui a determinação do "eu" ou dito "sujeito pós-metafísico",

2 DERRIDA, J. Khôra. Paris: Galilée, 1993.

3 DERRIDA, J. Foi et Savoir. Paris: Seuil, 2000.

4 DERRIDA, J. Timpanizar - a Filosofia. In. ___ Margens da Filosofia. Tradução de António M. Magalhães, J. Torres Costa, Lisboa: Rés ed., s/d, p. 11-25.

5 DERRIDA, J. Psyché. Inventions de l'autre, Paris: Galilée, 1987. p. 27. Jacques Derrida define a Desconstrução como uma experiência (no sentido de provação) aporética do impossível.

6 Veja-se, nomeadamente, DERRIDA, J. Um bicho-da-seda de si. In: CIXOUS, H.; DERRIDA, J. Véus ... à vela. Tradução de Fernanda Bernardo, Quarteto, Coimbra, 2001, p. 67. Vadios, trad. Gonçalo Zagalo, Hugo Amaral, Fernanda Bernardo, Palimage / Terra Ocre, Coimbra, 2010, p. 146; Séminaire. LaPeine de Mort, vol.1 (1999-2000), Galilée, Paris, 2012, p. 302; e etc. 
ou talvez mais precisamente ainda e como Derrida o designa, do quem, do quem vivo e da problematicidade que envolve a sua determinação em "sujeito". Questões tais como: designar-se-á o dito "sujeito pós-metafísico" ainda "sujeito"? E como escutar e entender, bem escutar e bem entender este "pós" no sintagma pós-metafísico? No pressuposto de uma temporalidade no decurso da qual este outro "sujeito", este novo ou renovado "sujeito" vem depois do "sujeito metafísico"? Quero dizer, vem a seguir ao "sujeito metafísico", cuja existência é suposto ter acabado, de uma vez por todas, em tal data? Qual a latitude e qual a elasticidade desta data? De onde data e até onde data ela? O que é afinal o "sujeito metafísico"? O que é, afinal, em que consiste, a determinação conceptual do "sujeito metafísico"?

Em suma, de que é que se fala, ou de "quem" é que exatamente se fala, quando se fala de "sujeito metafísico"? De uma fábula? De uma ficção imaginária? De um fantasma? Talvez! E talvez porque, quer disso, tenhamos consciência quer não, o que é afinal o dito "sujeito metafísico" senão uma fábula, como o saudoso e muito admirado Jacques Derrida no-lo lembrou e no-lo ensinou?"Le sujet est une fable", disse ele a Jean-Luc Nancy no título, admirável de precisão e de graça, "Il faut bien manger" ou "le calcul du sujet".

Mas se, por destino e condição, o "sujeito" é de fato uma fábula ${ }^{8}$, uma

7 “Le sujet est une fable". DERRIDA, J. Il faut bien manger ou le calcul du sujet. In:

Points de Suspension, Paris: Galilée, 1992. p. 279.

8 Que a determinação metafísica do sujeito advém de uma leitura da própria história da filosofia pouco atenta à textura ou à heterogeneidade dos textos filosóficos, e portanto aos seus detalhes ou às suas margens, comprovam-no os seguintes exemplos:

- Lembremos o "daimon" socrático - que se terá silenciado no momento da condenação à morte do filósofo (Apologia 40 d) - e o "pensamento alado" (Fedro, 244 a" de Platão).

- Lembremos Descartes e o seu pensamento de um cogito finito assediado ou hetero-afectado pelo infinito, assim pensando, como Levinas o sublinhou, mais do que o que pode pensar: numa palavra, assim desejando.

- E lembremos que, em Husserl, é no interior do presente vivo, a Urform da experiência transcendental, que, no telos da redução fenomenológico-transcendental, no seu solipsismo originário e necessário, o sujeito apodíctico é afectado pela experiência originária e apresentativa do alter-ego. Alter-ego que não pode, no entanto, apresentar-se, que não pode tornar-se uma presença originária para o ego. De facto, não pode haver senão uma apresentação analógica do alter-ego, que, como o próprio Husserl o sentiu, não pode nunca ser dado "em pessoa" - resiste absolutamente ao princípio dos princípios da fenomenologia: o dado intuitivo da presença originária. Esta hetero-afecção do ego puro, esta deslocação do ego puro a partir do outro e do tempo não leva apenas a um além da 
fábula poderosíssima - como tentarei demonstrá-lo já de caminho - esse, contra todas as evidências do senso comum ou mesmo do bom senso filosófico, nunca ninguém terá visto um tal "sujeito" a passear-se por aí, na natureza - como Derrida o diz, a dado momento, tanto do "eu" como do "nós", em D'ailleurs, Derrida, o filme de Safa Fathy: "alguém viu por aí um eu?", pergunta. E, irônico, responde: “eu não!" -, mas se por destino e condição o "sujeito" é de fato uma fábula, dizia, não é também menos verdade que a questão do dito "sujeito", seja na velha tradição repensada do hypokeimenon e do subjectum enquanto quodsubstat, seja na tradição do "quem", do "quem sou eu?", do "quem é si mesmo?" [penso aqui em

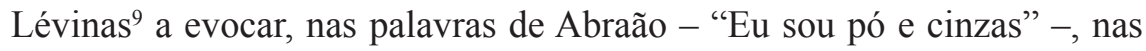
palavras de Moisés e de Aarão: "Não somos nada", Ex. 16, 8], seja, mais radicalmente ainda, na justa tradição da questão do "quem" vivo, não é também menos verdade, dizia, que a questão do "sujeito"se encontra hoje

Fenomenologia - leva à sua impossibilidade;

- E lembremoso Eterno Retorno do absolutamente outro de Nietzsche e a condição de promessa do seu "super-homem";

- E lembremos Heidegger que, criticando, a partir da sua Fundamentalontologie, a hegemonia moderna do sujeito da representação e do princípio de razão, evita (vermeiden, é a palavra do filósofo em Sein und Zeit (1927)) mesmo o uso do termo de "sujeito", que substitui pelo de "Dasein" (ser oai") lançado (Geworfenheit) no mundo com outros (in-der-Welt-sein).

- E lembremos que Freud fala, por um lado, do mito pelo qual o "eu" se desliga da psicologia de massas e se destaca do fundo de um "isso" na forma de um "eu" (cf. Psychologie des masses et analyse du moi), e, por outro lado, fala da tarefa in-finita, quer dizer, de cada vez finita, do devir do "eu" assediado pelo "inconsciente" : "onde isso estava devo eu tornar-me";

- E lembremos o “descentramento" do sujeito em Lacan :"Le noyau de notre être ne coïncide pas avec moi. C'est le sens de l'expérience analytique, et c'est autour de cela que notre expérience s'est organisée, et a déposé ces strates de savoir qui sont actuellement enseignées. Mais croyez-vous qu'il suffise de s'en tenir là, et de dire-le je du sujet inconscient n'est pas moi ? Cela ne suffit pas, car rien, pour vous qui pensez spontanément, si l'on peut dire, n'implique la réciproque. Et vous vous mettez normalement à penser que ce $j e$, c'est le vrai moi. [...] Ainsi, ce décentrage essentiel à la découverte freudienne, vous l'avez fait, mais aussitôt vous l'avez réduit.". LACAN, J. Le Séminaire, Livre II, Paris : Seuil, 1978. p. 59.

- E lembremos, enfim, Levinas, e o seu "eu des-inter-essado".

9 LEVINAS, E. Qui est soi-même. In: Nouvelles Lectures Talmudiques. Paris: Minuit, 1996, p. 77 ss. 
em dia, como reiteradamente Derrida também o sublinhou ${ }^{10}$, no centro das nossas mais prementes e talvez mais angustiantes inquietações - de fato, quer se trate do nascimento quer da morte e do "dar a morte" (no homicídio, no suicídio e na pena de morte), da axiomática a operar nas questões biotecnológicas ligadas à doação e ao transplante de órgãos, ao tratamento do esperma e do óvulo, à inseminação artificial e às chamadas "barrigas de aluguel", à descodificação do genoma humano e à criteriologia acreditada para a determinação (ou para a provocação) "eutanásica" da morte (como justificar aqui a referência dominante à consciência, ao querer, à vontade, ao córtex, pergunta Derrida?), tal como para a execução da pena de morte ${ }^{11}$; enfim, quer se trate da ética, do direito, dos direitos humanos, da política, da democracia, da técnica e das tele-tecnologias, da animalidade e da ecologia, da dita bioética ou da dita biopolítica, a questão do "sujeito" - que é também, e também sempre, a questão do "sujeito" em questão - é uma questão omnipresente e assediante, e jamais inatual. Mais atual do que nunca, na sua perene intempestividade, a questão do próprio ou da essência do homem coloca-se hoje em dia na urgência concreta e quotidiana ao sábio, ao filósofo, ao legislador, ao religioso, ao cidadão em geral nas suas relações com a terra, com o meio-ambiente, com o outro, com a vida e a morte.

Dito isto, - e dito isto na intenção de recolocar filosoficamente a questão do dito "sujeito" no ângulo a partir da qual aqui a repensarei a partir de Derrida e com Derrida, isto é, a partir da originariedade e da aporeticidade do luto -, se o sujeito é, de fato, uma fábula, uma fábula poderosíssima, aliás, da qual decorre ou que acompanha a determinação onto-teológica da soberania na nossa tradição greco-abraâmica ${ }^{12}$, não há também como negar a existência de uma história do pensamento metafísico-antropológico do sujeito - uma história na qual o "sujeito" é, no essencial, retratado na figura do sujeito da

${ }^{10}$ Le sujetest une fable, J. DERRIDA, «1992 Il faut bien manger» ou le calcul du sujet» in Points de Suspension, p. 297-298.

${ }^{11}$ BERNARDO, Fernanda. Desconstrução da Pena de Morte. In: Jacques Derrida. Col. Cultura, Media e Artes, Portugal: Unyleya, 2014.

${ }^{12}$ Da soberania na multimodalidade das suas configurações possíveis - a soberania de Deus, do sujeito, da vida, da morte, do homem, da pessoa, do princípio, do chefe, do monarca, do presidente, do povo (demos), do cidadão, da língua, da razão, da consciência, do inconsciente, do pai, do irmão, do marido, da polis ou do Estado-nação, da internacionalidade, da mundialização etc. 
enunciação, melhor, da autoenunciação e da representação, do domínio de si, da adequação de si a si, consciência, liberdade, responsabilidade e vontade, centro e origem $e$ de si $e$ do mundo: numa palavra, uma história na qual o sujeito é retratado em termos determinantemente autonômicos, egológicos e/ou egocráticos. Como se o "eu tivesse assistido à criação do mundo, e como se [o] eu só pudesse encarregar-[se] de um mundo que resultasse do [seu] livre arbítrio. Presunções de filósofos, presunções de idealistas. Ou demissão de irresponsáveis" ${ }^{13}$, estigmatiza também Emmanuel Levinas em Autrement qu'être ou au-delà del'essence (1974).

Re-pensar ou desconstruir - e repensar ou desconstruir, porque desconstruir é pensar ou repensar, e pensar ou repensar, porque, para Derrida, pensar é sempre re-pensar (de novo e diferente ou inventivamente ${ }^{14}$ ) - repensar ou desconstruir, dizia pois, a forma egológica da subjetividade ou da inter-subjetividade do dito "sujeito" não é também pura e simplesmente destruí-lo, liquidá-lo ou declarar a sua morte, como num furor apocalíptico o fizeram os Estruturalismos, que, numa certa ${ }^{I 5}$ peugada do "je est un autre" de Rimbaud, proclamaram que "todo o humano está fora" se desvaneceria, como à beira do mar um rosto de areia" 17

Repensar o "sujeito" é, em primeiro lugar, começar por referir que o dito "sujeito" da metafísica substancialista ou subjetivista é na verdade um logro, uma ficção, um fantasma, mostrando com Derrida, a partir da originariedade do luto, justamente, que não há identidade ${ }^{18}$ una ou própria, que nunca houve nem haverá identidade a si, ou presença-a-si, ou relação-a-si (do "si” ou do dito "sujeito") sem desvio, sem deslocação, sem interrupção,

${ }^{13}$ LEVINAS, E. De outro modo que ser, ou para lá da essência. Tradução de José Luiz Pérez e Lavínia Leal Pereira, Lisboa: Centro de Filosofia da Universidade de Lisboa, 2011. p. 138.

${ }^{14}$ DERRIDA, J. Penser ce qui vient. In: MAJOR, R. Derrida pour les temps à venir. Paris: Stock, 2007. p. 20.

${ }^{15}$ E numa certa peugada, porque o ditame de Rimbaud é igualmente pensável no contexto da meta-ética levinasiana e da desconstrução derridiana. LEVINAS, E. Humanisme de l'autre Homme, Montpellier: Fata Morgana, 1972. p. 102-106.

${ }^{16}$ LEVINAS, E. 1972, p. 103.

${ }^{17}$ FOUCAULT, M. As Palavras e as Coisas. Lisboa: Portugália, s/d.

18 "Uma identidade nunca é dada, recebida ou alcançada, não, apenas existe o processo interminável, indefinidamente fantasmática, de identificação". DERRIDA, J. O Monolinguismo do Outro. Tradução de Fernanda Bernardo. Porto: Campo das Letras, 2001, p. 43. 
sem divisão, sem separação, sem luto. Numa palavra, sem différance. O que é imediatamente sugerir a configuração do dito "sujeito" ou do "eu" em termos de relação - de relação dissimétrica hetero-auto-nômica: ou seja, de uma relação de ininterrupta hetero-auto-afecção $e$ ao outro $e$ a si mesmo como outro. Uma relação que se atesta, quer no sintagma levinasiano, ainda de recorte antropocêntrico, de "outro-no-mesmo", do "eu refém"do outro que é primeiro, quer no sintagma derridiano de "chez-soi chez l'autre", ou de "outro em mim": um outro que, originária e abissalmente, intima e enluta o "eu", cujo íntimo está assim, saiba-o ele ou não, queira-o ele ou não, antecipada e abissalmente intimado e tomado pelo outro antes de si, e, portanto, em si fora de si. Ou seja, esta relação hetero-autonômica (estruturante da singularidade, da ipseidade ou da "subjectividade do sujeito" em sede desconstrutiva) tem como que um duplo recorte e/ ou um duplo alcance - é, por um lado, uma relação dissimétrica hetero-autonômica ao outro e à língua $d o$ outro na sua primazia absoluta, e é, por outro lado, uma relação dissimétrica hetero-autonômica da unicidade ou da singularidade do "eu" na sua diferença $a$ si (que não na sua diferença consigo), instituindo-se ou constituindo-se a própria egoidade do ego nesta différance a $\mathrm{si}^{19}$. Ou seja, a primeira relação - a relação ao outro como outro - dobra-se na segunda, na relação diferencial do "eu" a si, assim o dividindo, ou assim o hetero-auto-afetando. Assim originariamente o enlutando. Noutros termos: assim o ex-apropriando ${ }^{20}$. $\mathrm{O}$ ex- da ex-apropriação do próprio "eu" marca a originariedade e a aporeticidade do luto fiel.

É o que passo agora atentar referir ao rés do pensamento e da obra de Jacques Derrida, que homenageamos hoje aqui, lembrando, como ele nos lembra e nos ensina, a originariedade do luto do animal que o "eu" é e "segue"21, que o mesmo é dizer, lembrando a originariedade do luto inerente a um vivente finito ou mortal que vem ao mundo atrasado em relação ao próprio mundo, em relação a si, em relação ao outro e aos outros, que não é portanto origem nem de si nem do mundo. É o que passo agora a fazer lembrando, em suma, a originariedade e a aporeticidade do luto no processo de individuação do "eu" - é também o que Derrida designa por "circuncisão"

\footnotetext{
${ }^{19}$ Veja-se, nomeadamente, J. DERRIDA, O Monolinguismo do Outro, op.cit.,2001, p. 100.

${ }^{20}$ Para o sincategorema "exappropriation". DERRIDA, J. Écographies, de la télévision, Paris: Galilée, 1966, p. 91-93; 123-124.

${ }^{21}$ DERRIDA, J. L'animal que donc je suis, Paris: Galilée, 2006.
} 
-, assim lembrando, por conseguinte, a autodesconstrução do dito "sujeito". Como também o dizem os versos de John Donne: "Nenhum homem é uma ilha, um todo em si [...]. Não mandes nunca, por isso, perguntar por quem tocam os sinos a finados: é por ti que eles tocam"22.

Esta originariedade do luto - que, notemo-lo, decapita a soberania fantasmática do "cogito, ergo sum", de Descartes, do "Ich denke", de Kant e de Hegel, do sujeito da representação e do princípio de razão que, segundo Heidegger, terá configurado a época das concepções/representações do mundo ${ }^{23}$ - esta originariedade do luto, dizia, é o grande esquecimento desta tradição metafísica de pendor hegemonicamente autonómico e, ipso facto, egocrático ou ipsocrático: de fato, como Derrida nos lembra e nos ensina, o luto não espera. A cada instante e no próprio gume do instante, o luto espreita-nos, espera-nos e alcança-nos antes mesmo de nós - antes mesmo de sermos ou de nascermos para nós próprios: com efeito, o luto, a experiência do luto, não ocorre apenas quando a perda ou a morte de alguém querido, quando uma perda e/ou uma morte que sofremos e carregamos: não, de todo! O luto é originário. Absolutamente originário - como Derrida o diz em Carneiros -, (o luto) enluta cada um de nós "com um implacável futuro anterior" ${ }^{\prime 2}$.

Vejamos agora em que termos, vendo ao mesmo tempo também em que termos o luto decide o destino e a incondição do dito "sujeito" na sua relação diferencial a si, como si-mesmo, por isso já sempre em autodesconstrução.

A experiência do luto (que, notemo-lo, é também a própria experiência como luto, isto é, como padecimento, como sofrimento, como pathos, como "experiência inexperienciada" (à Blanchot), uma experiência que não se faz, mas se sofre) é, em sede derridiana, a experiência da própria identificação do "eu" em termos de "experiência finita da não-identidade a si" ${ }^{25}$. E isto, porque, sintoma de uma finitude irredimível, de um impoder indialectizável, a experiência do luto é em Derrida, para Derrida, o paradigma por excelência

22 DONNE, J. Devotions upon Emergent Occasions, Meditation XVII, 1624.

${ }^{23}$ Heidegger, M. L'époque des "conceptions du monde. In: Chemins qui ne mènent nulle part, Tradução de Wolfgang Brokmeier, Paris: idées/Gallimard, 1962. p. 99 ss.

${ }^{24}$ DERRIDA, J. Carneiros. O diálogo ininterrupto: entre dois infinitos, o poema. Tradução de Fernanda Bernardo, Coimbra: Palimage, 2008. p. 16.

${ }^{25}$ DERRIDA, J. «Il faut bien manger» ou le calcul du sujet in Points de Suspension, op. cit., 1992, p. 280. 
da própria experiência do outro em "carne viva" - quero dizer, a própria experiência da relação ao outro como outro, isto é, como separado, como único e singular, absolutamente singular, como intangível, como inapropriável, como inacessível. Numa palavra, como secreto! Outrem é secreto porque é outro, é aliás um título de Derrida ${ }^{26}$. E, no contexto de uma meditação acercada aporia da fidelidade-infiel ao outro, que uma tal experiência do luto (ou da alteridade absoluta) configura, na sexta sessão do segundo volume do seu Seminário (2010) (A Besta e o Soberano), Derrida di-lo assim:

Digo "relação ao outro enquanto trabalho do luto", porque o luto não espera a morte - [o luto] é a própria essência da experiência do outro como outro, a experiência de uma alteridade inacessível e que não se pode senão perdê-la amando-a - ou igualmente odiando-a. Estamos sempre enlutados pelo outro. ${ }^{27}$

Estamos sempre enlutados pelo outro, sublinho, estamos sempre e desde sempre enlutados pelo outro, pela primaziada singularidade do outro relativamente a nós que, atrasados em relação ao mundo, ao outro, aos outros e a nós próprios, vimos a nós - como nós, justamente, como uma singularidade plural ou heterogeneizada, como "mais de um/a-menos de um/a"["plus d'un"] - através da incondicionalidade da nossa relação ao outro antes de nós e, paradoxalmente, em nós fora de nós e sempre, sempre diante de nós, intimando-nos, chamando-nos, endividando-nos, hiper-responsabilizando-nos. Gizando, pois, o luto a cena da relação ao outro como outro, e consubstanciando a sua originariedade a cena de uma experiência de identificação subjetiva por relação - por relação e como relação, como ininterrupta relação - com a primazia do outro na sua alteridade inacessível. Espectral. Secreta. Absolutamente secreta. Uma experiência de identificação

${ }^{26}$ DERRIDA, J. Outrem é secreto porque é outro. In: Papel Máquina. Tradução de Evando Nascimento, Revisão técnica Anamaria Skinner, São Paulo: Estação Liberdade, 2004. p. 331-358.

27 "Je dis "rapport à autrui en tant que travail du deuil", car le deuil n'attend pas la mort, il est l'essence même de l'expérience de l'autre comme autre, d'une altérité inaccessible et qu'on ne peut que perdre en l'aimant - ou aussi bien en la haïssant. On est toujours endeuillé d'autrui.". DERRIDA, J. Séminaire. La Bête et le Souverain, II (2002-2003), Paris: Galilée, p. 242. 
que, notemo-lo também, dá conta da gênese conjunta da singularidade, da responsabilidade e da hospitalidade e, portanto, da gênese conjunta das grandes questões éticas, jurídicas e políticas em torno das quais se constituíram e se constituem, quer a metafísica da subjetividade, quer a sua autodesconstrução. Como reiteradamente Derrida lembra, a desconstrução não é um método que, de fora, violentaria algo - um texto, uma obra, uma interioridade inencetada. Não, de todo: a desconstrução está já sempre no texto ou no foro íntimo de uma qualquer pretensa interioridade una, exapropriando-a de si, autodesconstruíndo-a a partir da sua interioridade já sempre abissalmente aberta. Desde sempre, desde sempre e por todo o lado, há "de la déconstruction à l'oeuvre"28.

Mas, se para Derrida a experiência da originariedade do luto consubstancia a experiência da própria identificação do "eu" ou do dito "sujeito" - da singularidade no idioma de Derrida - em termos de relação hetero-autonómica e dissimétrica por relação com a primazia da alteridade absoluta, abramos aqui um breve parenteses para inscrever a latitude do idioma derridiano, no tocante a esta mesma problemática, no contexto da nossa tradição greco-abraâmica e, especificamente, no contexto da contemporaneidade filosófica. Assim:

- enquanto a Fundamentalontologie de M. Heidegger - lembremo-lo sumariamente também - questionou e repensou o "sujeito" moderno da representação e do princípio de razão em termos de um Dasein lançado ["Geworfenheit"] no mundo com outros ["in-der-Welt-mit-Dasein"], e diagnosticou a ocidentalidade filosófica como um esquecimento do ser ["Seinsvergessenheit"] no sentido de um esquecimento da diferença ôntico-ontológica;

- e enquanto Emmanuel Levinas diagnosticou a ocidentalidade filosófica como um esquecimento do outro absoluto como rosto humano antes e para além do ser na sua marcha conquistadoramente galopante através da autonomi $^{29}$, dando-nos a pensar quer a filosofia quer a subjetividade do

${ }^{28}$ DERRIDA, J. Les arts de l'espace. In: . Penser à ne pas voir. Paris: Éd. de la différence, 2013. p. 54.

29 “Aussi la pensée occidentale parut-elle très souvent exclure le transcendant, englober dans le Même tout Autre et proclamer le droit d'aînesse philosophique de l'autonomie". LEVINAS, E. La Philosophie et l'Idée de l'infini. In: avec Husserl et Heidegger, Paris: Vrin, 1988. p. 166. .En Découvrant l'Existence 
sujeito ético-metafísico em termos explícita e assumidamente heteronómi$\cos ^{30}$ no âmbito de uma "ética" ou de uma "meta-ética" do semelhante ou da fraternidade (humanista e falocêntrica, pois);

- Jacques Derrida, esse, não só nos coloca na senda de um absolutamente outro que é absolutamente todo e qualquer outro - segundo o sintagma intraduzível na economia do seu idioma "tout autre est tout autre"31 -, como, no tocante à questão da dita "subjectividade do sujeito", diagnostica-a como um esquecimento da originariedade do luto e repensa-a em termos hetero-autonômicos ou desconstrutivos. Em autodesconstrução. Um esquecimento da originariedade do luto que tem como contraponto o fantasma ou a ficção, de fundo onto-teológico e autoimunitário, da soberania do "sujeito", do "eu", do "cogito"ou da "razão" - soberania essa que se manifesta nos efeitos e nos traumatismos da violência, das colonizações, dos imperialismos, dos fundamentalismos, dos totalitarismos em geral, das guerras, dos assassinatos, da própria pena de morte etc. E manifesta-se nestes efeitos traumáticos como um traumatismo deste traumatismo originário significado pelo luto originário - que, como Derrida diz em O Monolinguismo do Outro, são já sempre traumatismos de traumatismo. Traumatismos sobre traumatismo sem que nenhum perca a sua singularidade.

Porque, é precisamente a este "eu" originariamente enlutado e, por conseguinte, como que intimado e endividado, dividido e hiper-responsabilizado pelo outro e para o outro que, em Carneiros, Derrida designa por "cogito do adeus": um cogito em eterna saudação/eterna despedida do outro, em ininterrupta relação ao outro a partir do qual vem a si e se reafirma. E um cogito que deverá também escutar-se e entender-se como um adeus ao cogito ou, pelo menos, como um adeus a uma certa concepção do "cogito, ergo sum"32, o sintagma que enuncia o ponto arquimédico sobre o qual

30 “[...] si l'essence de la philosophie consiste à remonter en deçà de toutes les certitudes vers le principe, si elle vit de critique, le visage d'Autrui serait le commencement même de la philosophie. Thèse d'hétéronomie qui rompt avec une tradition très vénérable". (LEVINAS, 1988, p. 178).

${ }^{31}$ DERRIDA, J. Politicas da Amizade. Tradução de Fernanda Bernardo, Porto: Campo das Letras, 2003. p. 36; Dara Morte, trad. Fernanda Bernardo, Palimage / Terra Ocre, Coimbra, 2013,p. 104 ss.

32 Para a desconstrução deste, veja-se, nomeadamente, DERRIDA, J. Ego Sum, Paris: Aubier Flammarion, 1979. 
Descartes fundou três séculos de modernidade - uma modernidade lavrada em "terra firme", e não no lodo e na areia, como o filósofo o adverte no seu Discurso do Método e nas suas Meditações ${ }^{33}$, e que Husserl viria mais tarde a designar como a "proto-fundação cartesiana do conjunto da filosofia dos tempos modernos" 34 . Eis a designação do "cogito do adeus" em Carneiros, numa passagem na qual o filósofo precisa o seu pensamento da melancolia, ou do luto impossível, no contexto de um repensar desconstrutivo do diálogo hermenêutico (incapaz, nomeadamente, de atentar no modo como se entra no diálogo):

Um cogito do adeus, esta saudação sem retorno, assina a própria respiração do diálogo, do diálogo no mundo ou do diálogo mais interior. O luto não espera mais então. Desde este primeiro encontro, a interrupção vai ao encontro da morte, precede-a, enluta cada um com um implacável futuro anterior. Um de nós dois deverá ficar sozinho, antecipadamente ambos o sabíamos. E desde sempre. Um dos dois terá sido votado, desde o começo, a portar [porter] sozinho, em si mesmo, e o diálogo que lhe é preciso prosseguir para além da interrupção, e a memória da primeira interrupção.

$\mathrm{E}$, diria eu sem a facilidade de uma hipérbole, o mundo do outro. $\mathrm{O}$ mundo depois do fim do mundo.

Porque de cada vez, e de cada vez singularmente, de cada vez insubstituivelmente, de cada vez infinitamente, a morte não é nada menos que um fim do mundo. Não somente um fim entre outros, o fim de alguém ou de alguma coisa no mundo, o fim de uma vida ou de um vivente. A morte não põe um termo a alguém no mundo, nem a um mundo entre outros, ela marca de cada vez, de cada vez no desafio da aritmética, o fim absoluto do único e mesmo mundo, do que cada um abre como um só e mesmo mundo, o fim do único mundo, o fim da totalidade do que é ou pode apresentar-se como a origem do mundo para um determinado e único vivente - seja ele humano ou não. ${ }^{35}$

${ }^{33}$ DESCARTES, R. O Discurso do Método e Meditações. In: Obra Escolhida. Tradução de J. Guinsburg e Bento Prado Júnior, São Paulo: Difusão Europeia do Livro, 1962. p. 41-48, 117-136.

${ }^{34}$ HUSSERL, La Crise des Sciences Européennes, Paris: Gallimard, 1987. p. 484.

${ }^{35}$ DERRIDA, J. Carneiros, 2008, p. 16. 
Sem tempo para salientar aqui a proximidade de Derrida (ao nível da sua desconstrução do antropocentrismo dominante na ocidentalidade filosófico-cultural) com a insinuação de Clarice Lispector de um humano atento a sondar os confins do a-humano ou do inumano ${ }^{36}$, atentemos então agora mais de perto nesta originariedade do luto com o intuito de atentarmos precisar um pouco mais de perto ao rés da obra de Derrida - o filósofo explicita-a num momento de luto dele próprio pelo amigo Paul de Man numa belíssima passagem de "Mnemosyne" (1984) em Mémoires pour Paul de Man - diz aí:

Nós não somos nunca nós mesmos, e entre nós, idênticos a nós, um "eu" não está nunca em si mesmo, idêntico a si mesmo, esta reflexão especular não se fecha nunca sobre si mesma, não aparece antes desta possibilidade do luto, antes e fora desta estrutura de alegoria e de prosopopeia que antecipadamente constitui todo "ser-em-nós", "em-mim", entre nós ou entre si. O Selbst, o self, o si-mesmo não aparece senão nesta alegoria enlutada, nesta prosopopeia alucinatória - e antes mesmo de a morte do outro chegar efectivamente, como se diz, na "realidade". [...] tudo quanto inscrevemos no presente vivo da nossa relação aos outros porta já, sempre, uma assinatura de memórias de além-túmulo. ${ }^{37}$

${ }^{36}$ LISPECTOR, Clarice, Op. Lembremos: "Minha vida não tem sentido apenas humano, é muito maior - é tão maior que, em relação ao humano, não tem sentido [...]. Mas agora, eu era muito menos que humana - e só realizaria o meu destino especificamente humano se me entregasse, como estava me entregando, ao que já não era eu, ao que já é inumano.” p. 174-175

37 'Si la mort arrive à l'autre et nous arrive par l'autre, l'ami n'est plus qu'en nous, entre nous. En lui-même, par lui-même, de lui-même, il n'est plus, plus rien. Il ne vit qu'en nous. Mais nous ne sommes jamais nous-mêmes, et entre nous, identiques à nous, un "moi" n'est jamais en lui-même, identique à lui-même, cette réflexion spéculaire ne se ferme jamais sur elle-même, elle n'apparaît pas avant cette possibilité du deuil, avant et hors de cette structure d'allégorie et de prosopopée qui constitue d'avance tout "être-ennous", "en-moi", entre nous ou entre soi. Le Selbst, le self, le soi-même ne s'apparaît que dans cette allégorie endeuillée, dans cette prosopopée hallucinatoire- et avant même que la mort de l'autre n'arrive effectivement, comme on dit, dans la "réalité. [...] tout ce que nous inscrivons dans le présent vivant de notre rapport aux autres porte déjà, toujours, une signature de mémoires d'outre-tombe". DERRIDA, J. Mnemosyne. In: . Mémoires pour Paul de Man, Paris: Galilée, 1988. p. 49. 
A originariedade do luto dá, pois, conta da "primeira vinda do outro" como outro até um "eu" que, por isso, é já sempre um "nós", sendo ao mesmo tempo a primeira vinda do "eu" a "si mesmo", como "si" ("soi"), justamente, ou como um "nós". Como um "singular plural", no léxico de J.-L. Nancy. Como "mais de um / não mais um" (plus d'un), no léxico de Derrida. Um "eu" hetero-auto-afetado - em desconstrução. O que constrói simultaneamente desconstrói.

se a Jemeinigkeit, a do Dasein ou a do eu [...] é constituída na sua ipseidade a partir de um luto originário, então esta relação a si acolhe ou supõe o outro dentro do seu ser-si-mesmo como diferente de si. E reciprocamente: a relação ao outro (em si fora de mim, fora de mim em mim) não se distinguirá nunca de uma apreensão enlutada. A questão de saber se é a partir da sua própria morte [a posição de Heidegger] ou a partir da morte de outrem [posição de Levinas] que se institui a relação à morte ou a certeza da morte vê assim a sua pertinência desde o início limitada. ${ }^{38}$

Então, sem luto, sem este luto $e$ do outro $e$ de si próprio (do luto de si próprio no seu próprio luto pelo outro ${ }^{39}$ ) não haveria, pois, "eu sou", "consciência", "cogito", "eu penso"; numa palavra, "sujeito" - o luto dá-nos a pensar uma zona pré-egológica e pré-subjetiva que desconstrói a forma egológica da subjetividade ou da inter-subjetividade: uma zona, um limite, um certo "algures" de onde provém justamente a sua pulsão de identificação. Uma pulsão que tanto pode manifestar-se e marcar-se em termos de poder (autoimunizando-se do outro em fenômenos de desrespeito, de alergia e de violência para com outrem nas figuras da compreensão, idealizante e

38 "si la Jemeinigkeit, celle du Dasein ou celle du moi [...] est constituée dans son ipséité d'un deuil originaire, alors ce rapport à soi accueille ou suppose l'autre au-dedans de son être-soi-même comme différent de soi. Et réciproquement : le rapport à l'autre (en soi hors de moi en moi) ne se distinguera jamais d'une appréhension endeuillée. La question de savoir si c'est à partir de sa propre mort ou de la mort d'autrui que s'institue le rapport à la mort ou la certitude de la mort voit ainsi sa pertinence d'entrée de jeu limitée.”. DERRIDA, J. Apories. Paris: Galilée, 1996. p. 111.

${ }^{39}$ DERRIDA, J. Apories. Paris: Galilée, 1996; Dar a Morte, trad. Fernanda Bernardo, Palimage, Coimbra, 2013. 
apropriadora, do colonialismo, do imperialismo, do fundamentalismo, do assassinato, da pena de morte etc.), como em termos de vocação incondicional para a hospitalidade, para o acolhimento, para o amor, a amizade, a paz e a inventividade: a pulsão poética para o acolhimento e para a invenção ${ }^{40} \mathrm{e}$ a pulsão soberanista para o poder (a Bemächtigungtrieb de Freud), para a conquista, para a apropriação compreensiva ou violenta têm a mesma fonte - em O monolinguismo do outro Derrida designa este "algures" pré-egológico, que marca a passividade, a de-posição, ex-posição e ex-apropriação originárias do "eu"finito ou enlutado, de "alienação originária": uma "alienação sem alienação" ${ }^{\text {. E }}$ E uma "alienação sem alienação" porque, de fato, ela não aliena ainda nada de pré-existente - nenhuma ipseidade, nenhum "Eu", nenhum "cogito", nenhum "sujeito".

O "eu" e o "nós" de que então falamos", escreve o filósofo ainda em "Mnémosyne","não surgem ou não se delimitam como o que são senão através desta experiência do outro, e do outro como outro que pode morrer deixando em mim ou em nós esta memória do outro. A terrível solidão que é a minha ou a nossa na morte do outro, é ela que constitui esta relação a si a que se chama "eu", "nós", "entre nós", "subjectividade", "intersubjectividade", "memória". A possibilidade da morte "chega", se assim posso dizer, "antes" destas diferentes instâncias e torna-as possíveis. Há que precisar: a possibilidade da morte do outro como da minha ou da nossa instrói a minha relação ao outro e a finitude da memória. [...] o ser-em-mim ou o ser-em-nós constitui-se a partir da possibilidade do luto. ${ }^{42}$

${ }^{40}$ Lembramos que, para Derrida, a invenção da língua é o paradigma da invenção, ou, como o filósofo o diz numa importante nota de rodapé de Psyché, "a invenção da invenção" "L'invention du langage et de l'écriture - de la marque - est toujours, pour des raisons essentielles, le paradigme même de l'invention, comme si on assistait là à l'invention de l'invention.". DERRIDA, J. Invention de l'autre.. In: . Psyché. Inventions de l'autre. Paris: Galilée, 1987. p. 47, nota 1.

${ }^{41}$ DERRIDA, 2001, p. 39-40.

42 "Le "moi" et le "nous" dont nous parlons alors ne surgissent ou ne se délimitent comme ce qu'ils sont qu'à travers cette expérience de l'autre, et de l'autre comme autre qui peut mourir en laissant en moi ou en nous cette mémoire de l'autre. La terrible solitude qui est la mienne ou la nôtre à la mort de l'autre, c'est elle qui constitue ce rapport à soi qu'on appelle "moi", "nous", “entre nous", "subjectivité", "intersubjectivité", "mémoire". 
Portanto, "o ser-em-mim ou o ser-em-nós constitui-se a partir da possibilidade do luto". O que é dizer a originariedade do luto no processo de identificação do "eu". Vejamos agora um pouco mais de perto ainda como, em que termos, perguntando: o que é o luto? De que falamos nós, quando falamos de luto?

De fato, Derrida não nos deu ou não nos ensinou apenas a pensar o processo de identificação - como processo, justamente, e não como estado, como algo acabado, e não como uma identidade una e idêntica ${ }^{43}$ - a partir da originariedade do luto em sentido estrito ou como possibilidade geral - Derrida foi, como sempre, mais longe, e repensou também o próprio luto ${ }^{44}$ como uma espécie de paradigma da relação ao outro para além da sua teorização por Freud no célebre texto "Luto e Melancolia" ou dito "normal" - que, no fundo, consiste em "matar o morto", em aceitar a morte do outro carregando-o em si através de um movimento de idealização interiorizante, através daquela frase de derrota consolável (?) "é a vida!", ou através da "boa consciência de uma amnésia" -,diferentemente, pois, do luto dito "normal" de que se ocupam as brigadas de "psicólogos" a cuidarem das vítimas de catástrofes, a melancolia era, para Freud, o luto que não se fazia, que não lograva fazer-se, o luto que fracassava. Era um luto que Freud predicava de patológico - um luto impossível. Pois bem, para Derrida, este luto patológico, este luto impossível, este luto que teima em não se fazer, é o único luto possível - o único que salvaguarda o outro como outro, ou seja, respeitado no absoluto da sua alteridade. Eis como Derrida o diz em Carneiros:

Segundo Freud, o luto consiste em portar ou em carregar [porter] o outro em si. Não há mais mundo, é o fim do mundo para o outro na sua morte, e eu acolho em mim este fim do mundo, e devo portar [porter]

La possibilité de la mort "arrive", si je puis dire, "avant" ces différentes instances et les rend possibles. Il faut préciser: la possibilité de la mort de l'autre comme de la mienne ou de la nôtre instruit mon rapport à l'autre et la finitude de la mémoire. [...] l'être-en-moi ou l'être-en-nous se constitue depuis la possibilité du deuil"' (DERRIDA, 1988, p. 53).

${ }^{43}$ DERRIDA, 2001, p. 91.

${ }^{44}$ DERRIDA, J. Fors. In: ABRAHAM, N.; TOROK, M. Cryptonymie. Le verbier de l'homme aux loups, Paris: Aubier-Flammarion, 1976. p. 7-82.

${ }^{45}$ FREUD, S. La afliccion y la melancolia. In: . Obras Completas. Tradução de Luiz Lopéz-Ballesteros y de Torres, Madrid: Editorial Biblioteca Nueva, 1948. p. 1087-1095. 
o outro e o seu mundo, o mundo em mim: introjecção, interiorização da recordação (Erinnerung), idealização. A melancolia acolheria o fracasso e a patologia deste luto. Mas se eudevo (é a própria ética) portar [porter] o outro em mim para lhe ser fiel, para lhe respeitar a alteridade singular, uma certa melancolia deve protestar ainda contra o luto normal. Nunca ela deve resignar-se à introjecção idealizante. E deve rebelar-se contra o que Freud diz dele com uma segurança tranquila, como que para confirmar a norma da normalidade. A "norma" não é senão a boa consciência de uma amnésia. Ela permite-nos esquecer que guardar o outro dentro de si, como si mesmo, é já esquecê-lo. O esquecimento começa aí. É então preciso a melancolia. ${ }^{46}$

"É então preciso a melancolia", diz Derrida, insinuando ao mesmo tempo o registo hiper-ético da desconstrução ou do seu pensamento: é preciso. É devido. Em que consiste, pois, a melancolia na sua condição de luto impossivel? Na sua condição de um luto que se logra a falhar e que falha ao lograr-se? O filósofo explicita-o através daquilo a que chama o double bind autoimunitário inerente à aporia do luto, que é a cena de uma espécie de contradição irreparável, insolúvel, que, ao mesmo tempo, estrutura e arruína todo o trabalho de luto. Explicitemos: o luto logra-se a falhar na traição ou na infidelidade que deixa o morto lá fora, lá longe, sozinho, entregue a si mesmo, e, assim, assim e só assim, respeitado na sua alteridade infinita. É o luto que não toma, que não comporta, que não interioriza o outro/morto em si. Mas, mesmo neste luto que se logra a falhar, trai-se ainda assim o outro/morto que se deixa irremediavelmente de fora, abandonado e só, na sua singularidade ou na sua alteridade absoluta, entregue a si mesmo. Por outro lado e pelo contrário, o luto falha ao lograr-se, interiorizando, idealizando, conceptualizando, introjectando, compreendendo, assimilando o outro morto, que assim privamos da sua própria alteridade. Tal é a cruel aporia do luto impossivel: eis como Derrida a explicita ainda em "Mnemosyne":

Na morte do outro estamos votados à memória e, portanto, à interiorização, uma vez que o outro, fora de nós, não é mais nada; e, a partir da sombria luz deste nada, nós aprendemos que o outro resiste

\footnotetext{
${ }^{46}$ DERRIDA, 2008, p. 52.
} 
à clausura da nossa memória interiorizante. A partir do nada desta ausência irrevocável, o outro aparece como outro, e como outro para nós, na sua morte ou, pelo menos, na possibilidade antecipada de uma morte, uma vez que ela constitui e torna manifestos os limites de um eu ou de um nós tidos por albergar o que é maior e outro que eles fora deles neles. [...] Não podemos viver esta experiência senão na forma da aporia, da aporia do luto [...]: o possível permanece impossível, o sucesso falha, a interiorização fiel que porta o outro e o comporta em mim (em nós), vivo e morto ao mesmo tempo, faz do outro uma parte de nós, entre nós - e o outro parece então não ser mais o outro precisamente porque nós o choramos e o carregamos em nós, como uma criança ainda por nascer, como um porvir. Inversamente, o fracasso logra: a interiorização que aborta é ao mesmo tempo o respeito do outro como outro, uma espécie de terna rejeição, um movimento de renúncia que o deixa só, de fora, lá longe, na sua morte, fora de nós. ${ }^{47}$

A aporia do luto conjuga, pois, a fidelidade e a infidelidade (mas uma infidelidade por fidelidade, por excesso de fidelidade) ao outro-morto que, doravante, não podemos senão carregar no coração, no fundo do coração, no mais íntimo do íntimo, como uma espécie de in-finita declaração de amor sem palavras endereçadas à sua ausência, sem qualquer outra mediação sem solo, sem fundamento, sem mundo no fim do seu mundo, e no adeus, adeus sem fim, adeus impossível, ao fim do seu mundo: weltlos, dir-se-á,

47 “A la mort de l'autre, nous sommes voués à la mémoire, et donc à l'intériorisation puisque l'autre, au-dehors de nous, n'est plus rien; et depuis la sombre lumière de ce rien nous apprenons que l'autre résiste à la clôture de notre mémoire intériorisante. Depuis le rien de cette absence irrévocable, l'autre apparaît comme autre, et autre pour nous, à sa mort ou du moins dans la possibilité anticipée d'une mort, dès lors qu'elle constitue et rend manifestes les limites d'un moi ou d'un nous tenus d'abriter ce qui est plus grand et autre qu'eux hors d'eux en eux. [...] Nous ne pouvons vivre cette expérience que sous la forme de l'aporie, aporie du deuil [...] le possible reste impossible, la réussite échoue, l'intériorisation fidèle qui porte l'autre et le comporte en moi (en nous), vivant t mort à la fois, elle fait de l'autre une partie de nous, entre nous - et l'autre paraît alors n'être plus l'autre précisément parce que nous le pleurons et le portons en nous, comme un enfant encore à naître, comme un avenir. Inversement, l'échec réussit: l'intériorisation qui avorte, c'est à la fois le respect de l'autre comme autre, une sorte de tendre rejet, un mouvement de renoncement qui le laisse seul, dehors, là-bas, dans sa mort, hors de nous." (DERRIDA, 2008, p. 53-54). 
para apontarmos aqui de viés para a célebre tripla tese de Heidegger segundo a qual "1. A pedra [...] é sem mundo; 2 . O animal é pobre em mundo; 3 . O homem é configurador de mundo" "48, com a intenção de realçarmos aqui de passagem a contestação radical que Derrida faz desta tripla tese a partir da sua leitura interpretativa do último verso do poema "Grosse, Glühende Wolbung" de Paul Celan - o sublime "Die Welt ist fort, ich muss dich tragen", um dos dois versos de Celan que, justamente, a propósito da problemática da individuação do "eu", Jacques Derrida nos terá ensinado de cor: o outro verso que Derrida cita no próprio idioma de Celan é "Aschenglorie: (...) grub ich mich in dich und in dich" - no próprio idioma de Celan, quer dizer, dizendo a intraduzibilidade da sua assinatura po-ética.

Dizendo o luto impossível pela escrita, através da escrita - que está, ela, nas vezes do próprio luto, da impossibilidade do luto, de que é, portanto, um sintoma, um véu de luto -, este outro verso aparece quase no fim de "Um bicho-da-sede de si" no contex to de uma encenação poético-onírica do próprio processo de identificação pela escrita - uma encenação que realça o registo auto-bio-thanato-hetero-gráfico da escrita-mesmo da escrita filosófica - através da metáfora da sericicultura de um Jacques Derrida feito "bicho-da-seda": um J. Derrida que, lembramos, no contexto da ocidentalidade filosófica se tem a si mesmo pelo "eleito secreto" 49 dos animais - diante de quem e por quem temos também de responder, testemunhando-se a nossa responsabilidade, e portanto a nossa humanidade, neste responder. Cito esta passagem - um pouco longa - com a intenção de, nesta nossa homenagem a Jacques Derrida, salientar também o quão, grande pensador-filósofo, grande escritor era também Derrida:

Eu observava o progresso invisível da tecelagem, um pouco como se fosse surpreender o segredo de um prodígio, o segredo daquele segredo, a uma distância infinita do animal, desta pequena verga inocente, tão estrangeira mas tão próxima no seu distanciamento incalculável. Não posso dizer que me apropriava da operação, também não direi outra coisa ou o contrário. Aquilo de que me apropriava sem

\footnotetext{
48 "1. La pierre (ce qui est matériel) est sans monde; 2. L'animal est pauvre en monde; 3. L'homme est configurateur de monde.". HEIDEGGER, M. Les concepts fondamentaux de la métaphysique. Monde-Finitude-Solitude, Paris: Gallimard, 1992. p. 267.

${ }^{49}$ DERRIDA, J. L'animal que donc je suis. Paris: Galilée, 2006. p. 91.
} 
o revirar para mim, aquilo de que me apropriava lá além, lá fora, ao longe, era a operação, a operação através da qual o próprio bicho segregava a sua secreção. Ele segregava-a, à secreção. Segregava. Intransitivamente. Babava-se. Segregava absolutamente, segregava uma coisa que nunca seria um objecto dele, um objecto para ele, um objecto diante do qual ele estaria face-a-face. Ele não se separava da sua obra. O bicho-da-seda produzia fora dele, diante dele, o que nunca o abandonaria, uma coisa que não era outra coisa senão ele, uma coisa que não era uma coisa, uma coisa que lhe pertencia e lhe voltava como própria. Ele projectava para fora o que provinha dele e permanecia no fundo, no fundo dele: fora de si em si e junto a si, em vista de em breve o envolver completamente. A sua obra e o seu ser para a morte. A fórmula viva, minúscula mas ainda divisível do saber absoluto. A natureza e a cultura absolutas. A sericicultura não era de todo do homem, não era de modo algum a coisa do homem que cria os seus bichos-da-seda. Era a cultura do bicho-da-seda como bicho-da-seda. Secreção do que não era nem um véu, nem uma teia (nada a ver com a aranha), nem um lençol nem uma tenda, nem uma écharpe branca, esta pequena vida silenciosa e finita não fazia outra coisa, lá além, tão perto, debaixo dos meus olhos mas a uma distância infinita, para além disto: preparar-se a si-mesmo para se esconder a si-mesmo, amar a esconder-se, em vista de se produzir para fora e de aí se perder, cuspir aquilo mesmo de que o corpo se apoderava de novo para o habitar nele se embrulhando de noite branca. Em vista de retornar a si, de ter para si o que se é, de se ter e de se ser amadurecendo, mas morrendo também à nascença, de desmaiar no fundo de si, o que vem a ser enterrar-se gloriosamente na sombra no fundo do outro: "Aschenglorie: (...) grub ich mich in dich und in dich" ${ }^{\circ 0}$. O próprio amor. O amor fazia-se fazer amor sob os olhos

${ }^{50}$ Não sem observar a intraduzibilidade da força poética de "Aschenglorie" no idioma de Celan, arriscamos traduzir "Glória de cinzas: [...] enterro-me em ti e em ti". CELAN, P. Atemwende / Renverse du Souffle, ed. bilingue, tradução e anotação de Jean-Pierre Lefebvre. Paris: Seuil, 2003. p. 78-79. Para salientar a impossibilidade de traduzir a economia poética de "Aschenglorie", uma palavra que, em si mesma, é mais de uma, [plus d'une], lembramos de passagem aqui as suas diversas versões: André du Bouchet: "Cendres la gloire" ["Cinzas a glória"]; J.-P. Lefebvre: "Gloire de cendres" ["glória de cinzas"; Joa- 
da criança sonhadora.Porque esta não acreditava no que via, não via o que cria ver, já se contava uma história, esta história, como uma filosofia da natureza para caixa de sapatos [...] a saber, que o próprio bicho-da-seda se amortalhava, voltava a si mesmo na sua odisseia, numa espécie de saber absoluto, como se lhe fosse necessário embrulhar-se na sua própria mortalha, a mortalha branca da sua própria pele, para permanecer ao pé de si, o ser que ele tinha sido em vista de se reengendrar a si-mesmo na fiação dos seus fios-filhos ou das suas filhas - para além de toda a diferença sexual ou antes de qualquer dualidade dos sexos, e antes mesmo de todo o acasalamento. No começo houve o bicho que foi e não foi um sexo, a criança via-o bem, um sexo talvez, mas então qual? O seu bestiário começava. Esta filosofia da natureza era para ele, para a criança que eu era mas que continuo ainda, a própria ingenuidade, sem dúvida, mas também o tempo da aprendizagem infinita, a cultura de confecção, a cultura confeccionada segundo a ficção, a autobiografia do logro, Dichtung und Wahrheit, um romance de formação, um romance da sericicultura que ele começava a escrever em vista de o endereçar a si mesmo, de nele se erguer ele mesmo numa algazarra de cores e de palavras. ${ }^{51}$

$\mathrm{Na}$ impossibilidade de uma leitura atenta desta passagem (demasiado) longa, intensa e imensa, volto-me então agora para o outro verso de Paul Celan que Derrida nos ensinou de cor no idioma do próprio poeta - o verso"Die Welt ist fort, ich muss dich tragen" / "O mundo acabou, eu tenho de te portar" -, a fim de muito sucintamente o apontar como a assinatura po-ético-desconstrutiva do "eu" ou do dito "sujeito", segundo Jacques Derrida no seu insanável diferendo - que é também o diferendo da própria desconstrução como idioma filosófico - com a fenomenologia, com a hermenêutica heideggeriano-gadamariana, com o dialogismo de Buber, com o criticismo de Adorno, com a psicanálise freudiana e até mesmo com a meta-ética levinasiana: com efeito, este verso, "Die Welt ist fort, ich muss

chim Neugroschel: "Ash-Glory" [“cinza-glória"] e o próprio Jacques Derrida traduz por "Gloire pour les cendres" ["Glória para as cinzas"] e por "Gloire / de cendres" ["Glória / de cinzas" em Poétique et Politique du Témoignage. Paris: Éditions de l'Herne, 2005.

${ }^{51}$ J. DERRIDA, Um bicho da seda de si. In J. Derrida e H. Cixous, Véus ...à vela, op.cit, p. 75

-76 e Caderno de Leituras nº 29, Bichos-da-Seda, Chão da Feira, Julho 2014. 
dich tragen ", não diz poeticamente apenas o poema, o pensamento do poema segundo Derrida - poema que o filósofo diz ser a ferida áfona de outrem que um "eu" deseja aprender de cor: "de cor" 52 , ("par coeur", "auswendig"), quer dizer, "do coração", a partir do "coração" ou da "vida". Do chão da "vida". Para além, portanto, das "bibliotecas do saber", que ele incendeia. Não, este verso de Celan sugere também, diz também o pensamento do mundo e o pensamentoda dita "subjectividade do sujeito" segundo Derrida. Um pensamento que pensa o "eu" a partir do seu desvio oudo seu distanciamento (fort) do mundo, ou do horizonte do mundo [significado pelo "DieWelt ist fort,"] e, ipso facto, numa certa proximidade com o gesto da épochê fenomenológico-transcendenta $1^{53}$ - que levará à apodicidade do ego puro e das suas cogitationes - e no distanciamento quer doser-no-mundo do sujeito/Dasein de Heidegger, quer do próprio diálogo eu-tu de Buber, a fim de pensar e de nos dar a pensar o "eu" a partir da sua sujeição, da sua obrigação arqui-originária e hiper-responsável [significada pelo "ich muss dich tragen"] diante do outro, pelo outro e para o outro, aqui na designação do "tu", que ele está, à partida, obrigado a bem portar, a bem carregar como uma mãe carrega um filho no ventre ou como se porta o luto. O luto impossível. Isto é, na situação de "um no outro", de "um para o outro", no caso da gravidez na "solidão partilhada entre um e dois corpos", aí, onde, "o mundo desaparece, está longe, permanece um terceiro quase excluído". ${ }^{54}$

De notar também ainda que este "tu" de Derrida não é, nem o "tu" de Buber - que se encontra no mesmo plano do "eu" e, portanto, no âmbito de uma relação formal e recíproca ${ }^{55}$-, nem também o "outro homem" de Levinas, mas um " $t u$ " (dich) qualquer: um qualquer " $t u$ " que, no tocante à questão do "sujeito", permite traçar o diferendo da desconstrução derridiana em relação à meta-ética levinasiana e ao pensamento de Heidegger tanto do

52 "Ainsi se lève en toi le rêve d'apprendre par cœur. De te laisser traverser le cœur par la dictée. D'un seul trait, et c'est l'impossible et c'est l'expérience poématique. [...] J'appelle poème cela même qui apprend le cœur, ce qui invente le cœur", J. DERRIDA, Che cos'è la poesia? in Points de Suspension, Galilée, Paris, p. 306.

${ }^{53}$ Cf. E. Husserl, Meditações Cartesianas., Rés, Lisboa, s/d, . p. 34; Idées Directrices pour une Phénoménologie, § 49, Tel/Gallimard, Paris, 1950, p. 160-164.

${ }^{54}$ J. DERRIDA, Carneiros, op. cit., p. 51.

${ }^{55}$ Cf. E. Levinas, «Martin Buber». In Noms Propres., Fata Morgane, Montpellier, 1976, p. $36-43$. 
poema, como do mundo, do "humano"/Dasein e do animal. Diferença que não posso senão referir aqui, sem ter tempo para a desenvolver.

$* * *$

Em suma: o que este verso de Paul Celan lido por Derrida mostra é que, em sede desconstrutiva, o "eu" se pensa ou é pensado na sua ininterrupta relação de sujeição responsabilizante ao outro no distanciamento do mundo, ou na véspera do mundo. Mundo que, por sua vez, também só é pensado a partir da sujeição, tão endividante quanto hiper-responsabilizante, do "eu" em relação ao outro, na sua condição de uma outra origem do mundo. Em Carneiros, Derrida não podia ser mais claro na sua demarcação do pensamento do mundo de Heidegger, e, por conseguinte, na enfatização da singular "meta-eticidade" da Desconstrução e da sua diferença relativamente à Hermenêutica - diz aí:

Sobretudo, Heidegger tentou distinguir entre o que é weltlos, o que é weltarm e o que é welbildend. [...] Trata-se do grupo das três "teses" que Heidegger apresenta, aliás assim mesmo, pouco depois de Sein und Zeit, num seminário de 1929-1930 sobre o mundo, a finitude, a solidão (Welt-Endlichkeit-Einsamkeit): "Der Stein ist weltlos, das Tier ist weltarm, der Mensch ist weltbildend".

Por razões que não posso desenvolver aqui, nada me parece mais problemático do que estas teses.

O que é que se passaria se, no nosso poema, o Fort-sein do mundo, na sua instância própria, não respondesse a nenhuma destas teses ou destas categorias? Se as excedesse a partir de um lugar absolutamente outro [tout autre]? Se ele fosse tudo excepto privado de mundo (weltlos), pobre em mundo (weltarm) ou configurador de mundo (weltbildend)? Não é então o próprio pensamento do mundo que se deveria re-pensar a partir deste fort e, ele mesmo, a partir do ich muss dich tragen ${ }^{96}$

E é, justamente, este "eu" incondicionalmente obrigado diante de outrem na figura de um "eu devo" que se demarca do "eu sou", do "cogito,

\footnotetext{
${ }^{56}$ DERRIDA, Carneiros, op. cit., p. 55-56.
} 
ergo sum" e, portanto do registro ontológico, de índole substancialista ou não, da "subjetividade do sujeito". Por outras palavras: é este "eu devo" de princípio que desconstrói o "sujeito metafísico" - ou o lembra e o mostra em autodesconstrução. É ele que diz "adeus" à soberania do "cogito, ergo sum", lembrando-lhe a originariedade do luto na sua condição de "relação sem relação" (à Blanchot ${ }^{57}$ ) ao outro como outro.

$\mathrm{O}$ "cogito do adeus" é pois, e em suma, um "cogito" intimado e obrigado ao outro antes mesmo de ser-e no interdito de ser. E é precisamente este "eu" incondicionalmente obrigado a bem portar o outro em si - portando-o como outro, isto é, como uma alteridade salva-guardada -, que tanto configura o repensar derridiano-desconstrutivo do "cogito" como o seu adeus ao "cogito" ou ao "eu sou" - ao poder do "eu sou" / "eu posso", cuja autodesconstrução assim põe a nu. Derrida di-lo ainda em Carneiros, não sem ao mesmo tempo enfatizar uma vez mais também quer o registo hiperético quer aporético da desconstrução: a sua inevitável e ineliminável apor/eticidade - escutemo-lo:

E eu, eu não sou, não posso ser, não devo ser senão a partir desta estranha carga [portée] deslocada do infinitamente outro em mim. Devo portar [porter] o outro, e portar-te [te porter], o outro deve portar-me [me porter] [...] aí mesmo onde não há mais mundo entre nós ou sob os nossos pés para nos assegurar uma mediação ou consolidar uma fundamentação. Estou só com o outro, sou só dele e para ele, só para ti e teu: sem mundo. Imediatidade do abismo que me compromete com o outro por todo o lado em que o "eu devo" - "eu devo portar-te" - leva para sempre a melhor ao "eu sou", ao sum e ao cogito. Antes de ser, eu porto, antes de ser eu,eu portoo outro. ${ }^{58}$

Uma obra de Derrida datada de 1966, O monolinguismo do outro, dá-nos privilegiadamente a pensar este "eu" que, antes de ser e em vez de ser, porta elou suporta o outro, permitindo-nos como que concretizar esta experiência de identificação do "eu" através da sua relação com a singular anterioridade

\footnotetext{
${ }^{57} \mathrm{M}$. BLANCHOT, Le rapport du troisième genre». in L'Entretien Infini, Gallimard, Paris, p. 94-105.

58 J. DERRIDA, Carneiros, op. cit, p. 54.
} 
da língua (e não, notemo-lo, por relação com o solo ou o sangue ${ }^{59}$ ) na figura da Lei - da Lei da alteridade como língua ${ }^{60}$ que o filósofo aqui designa por "monolinguismo do outro": do outro no sentido de proveniente da primazia do outro como o próprio outro, que não pertença do outro. Como Derrida diz: uma língua não pertence! Jamais!

A "monolíngua do outro" consubstancia, pois, o limite a partir do qual nascemos para nós próprios e com o qual e no qual in-finitamente nos debatemos - um limite líquido, intransponível e inapropriável sem resto, uma espécie de fundo de amnésia e de afasia (a primeiríssima infância do infans (aquele que não fala, justamente)) que nos constitui, autodesconstruindo-nos. Na pegada repensada dos phisiologoi - que, lembremos, se perguntavam pelo elemento primordial, pela "archê" das coisas -, o "monolinguismo do outro" configura assim uma espécie delimite que, longe de nos limitar, apenas, nos desafia e assedia e, não obstante a nossa inconsolável finitude, no mesmo lance nos ilimita, nos in-finitiza também. Derrida di-lo assim em O monolinguismo do outro:

Sou monolingue. O meu monolinguismo demora-se e eu chamo-lhe a minha morada, e sinto-o como tal, nele me demoro e nele habito. Ele habita-me. O monolinguismo no qual respiro é mesmo para mim o elemento. Não um elemento natural, não a transparência do éter, mas um meio absoluto. Inultrapassável, incontestável: não posso recusá-lo senão atestando a sua omnipresença em mim. Ele ter-me-á sempre precedido: sou eu. Este monolinguismo, para mim, sou eu. [...] fora dele eu não seria eu-mesmo. Ele constitui-me, dita-me mesmo a ipseidade de tudo, prescreve-me, também, uma solidão monacal, como se quaisquer votos me tivessem ligado a ele antes mesmo de ter aprendido a falar. Este solipsismo inexaurível, sou eu antes de mim. Para sempre. ${ }^{61}$

Ou seja, o "monolinguismo do outro" é o "fundo de amnésia e de afasia" ${ }^{2}$ pré-egológia, pré-subjetiva e pré-ontológica a partir do qual o "eu"

\footnotetext{
${ }^{59}$ J. DERRIDA, O Monolinguismo do Outro, op. cit., p. 26.

${ }^{60}$ Ibidem, p. 56.

${ }^{61}$ Ibidem, p. 13-14.

${ }^{62}$ Ibidem, p. 99.
} 
vem a si na sua experiência in-finita de "ex-apropriação" $e$ da língua $e$ de si: na sua relação de "ex-apropriação" de si próprio por relação e na relação com a "monolíngua do outro", o "eu" inventa-se e reinventa a língua. Inventa-se reinventando - como $\mathrm{Eco}^{63}$ ! - a língua.

E é justamente este movimento in-finitamente contraditório de "ex-apropriação" de si e da língua, de "ex-apropriação" de si na sua "ex-apropriação" da própria língua - uma apropriação de cada vez expropriante que leva Derrida a proclamar, "eu não tenho senão uma língua, e ela não é minha" ${ }^{" 64}$, assim dizendo a experiência universal e universalizável da singularidade ou da ipseidade (ipse, ipsissimus) - é, pois, este movimento in-finitamente contraditório de "ex-apropriação" simultânea de si e da língua, de "ex-apropriação" de si na "ex-apropriação" da língua do outro, dizia, que desencadeia e exaspera todas as nossas paixões e todas as nossas esperanças, dando conta da perturbação ou da divisão abissal e infinita da identidade do "eu". Dando conta da autodesconstrução do dito "sujeito". É, de fato, esta "ex-apropriação" de princípio que desencadeia, quer a pulsão genealógica e soberanista (autoimunitária" ${ }^{55}$ - que, reitero, está na origem da pulsão de poder e se manifesta nas situações de colonização, de imperialismo, de fundamentalismo, de totalitarismo, de guerra, de alergia e de violência em geral para com outrem, que brotam da crença (porque, é de fato, uma crença) de uma identidade una e estável, própria, que procura imunizar-se e conjurar o medo da infecção -, quer a pulsão para a incondicionalidade da vocação para o acolhimento de todo e qualquer outro: vocação que, em Políticas de Amizade ${ }^{66}$, Derrida designa por predisposição para a "amância" [aimance] - uma espécie de véspera e de condição de possibilidade para a abertura incondicional ao outro e/ou ao porvir ${ }^{67}$, para a amizade e para

${ }^{63}$ BERNARDO, Fernanda. Eco-grafias. Dar à língua: contra-assinatura, re-invenção e sobrevivência. Ovídio - Derrida. Revista Filosófica de Coimbra, Coimbra, n. 39, p. 27-262. 2011.

${ }^{64}$ DERRIDA, 2001, p. 13.

${ }^{65}$ DERRIDA, 2000. DERRIDA, J. Auto-immunités, suicides réels et symboliques. In: DERRIDA, J. HABERMAS, J. Le "concept" du 11 septembre, Paris: Galilée, 2003, p. 133 ss ; Séminaire. La peine de mort. Volume I (1999-2000), Galilée, Paris, 2012.

${ }^{66}$ DERRIDA, J. Políticas da Amizade. Tradução de Fernanda Bernardo, Porto: Campo das Letras, 2003. p. 74-84.

${ }^{67}$ Para a relação existente entre "o outro", “a invenção" e o "porvir” (DERRIDA, 1987, p. 49-61). 
o amor. Numa palavra, como predisposição para o acolhimento prazeroso e esperançado do porvir (que em Derrida não é o futuro) ou da vida na sua economia da morte como sobrevida ou sobrevivência ${ }^{68}$ [survie/survivance].

Razão pela qual eu costumo dizer que um "derridiano" digno do nome, digno deste pensamento maior, muito maior do que nós, que nos desafia e que, na nossa condição de herdeiros responsáveis e admirativos, hoje e aqui homenageamos, é sempre, não sem risco, é certo, um amigo ou uma amiga. É, em todo o caso, a promessa intempestiva e inesperada de um amigo ou de uma amiga - ousemo-la, caros amigos e caras amigas, ousemos esta promessa em prol de um mundo mais justo por vir in memoriam do pensamento justo, tão justo de Jacques Derrida, com cujas derradeiras palavras endereçadas aos amigos e amigas, e lidas pelo filho mais velho à beira da sua sepultura, vos deixo, enfim, eu hoje aqui:

"je vous aime et vous souris d'où que je sois."

Data de registro: $14 / 04 / 2015$

Data de aceite: 22/04/2015

${ }^{68}$ Para esta questão, veja-se, nomeadamente, J. DERRIDA. J., Aprender finalmente a viver. "'Somos estruturalmente sobreviventes, marcados pela estrutura do rastro, do testamento. Mas, dito isto, não queria dar curso à interpretação segundo a qual a sobrevivência está mais do lado da morte, do passado, do que da vida e do porvir. Não, a desconstrução está, todo o tempo, do lado do sim, da afirmação da vida. Tudo quanto digo [...] da sobrevida [survie] como complicação da oposição vida/morte, procede em mim de uma afirmação incondicional da vida. A sobrevivência [survivance] é a vida para além da vida, a vida mais do que a vida, e o discurso que eu mantenho não é mortífero, pelo contrário, é a afirmação de um vivente que prefere a vida e portanto o sobreviver à morte, porque a sobrevida [survie], não é apenas o que resta, é a vida mais intensa possível»" (Tradução de Fernanda Bernardo, Ariadne, Coimbra, 2005. p. 55-56). 